\title{
ANÁLISE DAS EXPORTAÇÕES NA LÓGICA ESTRUTURALISTA-KALDORIANA: EVIDÊNCIAS PARA O BRASIL E A CHINA ${ }^{\circ}$
}

\author{
ANALYSIS OF EXPORTS IN THE STRUCTURALIST-KALDORIAN LOGIC: \\ EVIDENCE FOR BRAZIL AND CHINA \\ Joilson de Assis Cabral* \\ Maria Viviana de Freitas Cabral* \\ enviado: 09 abril 2018 - aceptado: 24 octubre 2018
}

\begin{abstract}
Resumo
Este trabalho analisou o papel das exportações brasileiras e chinesas sobre a capacidade de gerar crescimento econômico sustentado na lógica estruturalista-kaldoriana. A análise empírica consistiu em extrair, hipoteticamente, o setor externo de ambas as economias e, a partir disso, verificar o conteúdo tecnológico dos setores mais impactados. Para a China, os setores mais impactados foram os de alta e média intensidades tecnológicas. Este resultado sugere que a China endogeneizou o progresso tecnológico e alcançou um ciclo de crescimento econômico sustentado. Já para o Brasil, os resultados são preocupantes, afinal os setores mais impactados foram os de baixa intensidade tecnológica, com baixa elasticidade-renda. Assim, a economia brasileira sofreria restrição do balanço de pagamentos no longo prazo e entraria em um ciclo vicioso, inviabilizando o crescimento econômico sustentado do País.

Classificação JEL: C67, F43, O30.

Palavras-chave: conteúdo tecnológico das exportações, crescimento econômico, análise estruturalista-kaldoriana, modelo de insumo-produto, extração hipotética.
\end{abstract}

- De Assis Cabral, J., \& Freitas Cabral, M. V. (2019). Análise das exportações na lógica estruturalista-kaldoriana: evidências para o Brasil e a China. Estudios económicos, 36 (72), 31-61.

* Universidade Federal Rural do Rio de Janeiro. Correo electrónico: cabraljoilson@gmail.com, mvivianafreitas@gmail.com 


\begin{abstract}
This paper examined the role of the Brazilian and Chinese exports on the capacity to generate economic growth sustained following the Kaldorian-structuralist logic. The empirical analysis consisted in extracting, hypothetically, the external sector of both economies and, from this, to verify the technological content of the most impacted sectors. For China, the most impacted productive sectors were the sectors of high and medium technological intensities. This result suggests that the Chinese economy endogenized technological progress and achieved a cycle of economic growth sustained. For the Brazilian economy, the results are worrisome, since the sectors of low technological intensity, with low-income elasticity, were the most impacted. Thus, the Brazilian economy could suffer from a restriction of the balance of payments in the long run and could enter into a vicious cycle, making the sustained economic growth of the country unfeasible.
\end{abstract}

JEL Code: C67, F43, O30.

Keywords: Technological Content of Exports, Economic Growth, Input-Output Model, Hypothetical Extraction. 


\section{INTRODUÇÃO}

Recentemente, países emergentes como o Brasil e a China, em função do tamanho geográfico, população, nível de produto e mercado interno, têm despertado o interesse dos pesquisadores no sentido de entender os condicionantes do atual desempenho econômico (Vieira e Veríssimo, 2009). No início dos anos de 1990 estas duas economias passaram a ser importantes players no comércio mundial e na atração de fluxos de investimentos. Em 1995, a China ocupava a nona posição nas exportações mundiais enquanto o Brasil não figurava entre as economias mais dinâmicas em relação à exportação. Na década seguinte, em 2005, a economia chinesa passou a ser a terceira na classificação das exportações mundiais. Já o Brasil passou a ocupar a vigésima terceira posição no ranking das exportações mundiais levando à reversão do déficit da balança comercial apresentado nos anos de 1990 (WTO, 2006). Neste mesmo período, a média do investimento direto estrangeiro (IDE) em relação ao PIB situou-se em 4\% para a China, ao passo que no Brasil estes influxos de capital foram, em média, 2,85\% do PIB (World Bank, 2018).

O desempenho da balança comercial e a grande entrada de IDEs em ambas as economias no período compreendido de 1995 a 2005 resultou em boa performance de seus respectivos balanços de pagamentos (BP). Apesar da melhora do BP, existem diferenças consideráveis no desempenho econômico de tais países, visto que a China tem apresentado acentuadas taxas de crescimento econômico quando comparadas ao Brasil no período pós-década de 1990.

No caso específico da economia brasileira, o aprofundamento da abertura comercial na década de 1990 tinha como objetivo reduzir a estrutura de proteção industrial, eliminar barreiras não tarifárias, modernizar as instituições, mecanismos e instrumentos de política industrial e comercial (Nassif, 2000). A abertura comercial levou a indústria nacional à competição com produtos importados e, ao mesmo tempo, impôs grandes desafios à incipiente e protegida estrutura produtiva nacional. Com a consequente necessidade de redução de custos de produção e aumento de produtividade, vários setores passaram por processos de privatização, desverticalização e terceirização.

Neste intuito, a estratégia adotada pelo setor produtivo nacional consistiu em importar máquinas, equipamentos e sistemas visando aumentar a absorção e difusão da tecnologia na estrutura produtiva brasileira (Araújo, 2012). Tal estratégia culminou em contração de capacidade instalada, redução dos gastos em $\mathrm{P} \& \mathrm{D}$, aumento das importações de tecnologia e eliminação de postos de trabalho vinculados à área técnico-científica (Kupfer, 1998). Assim, Kupfer (ibid.) conclui que não 
houve esforço por parte da indústria brasileira em desenvolver novas tecnologias internamente, evidenciando fragilidades do sistema industrial brasileiro.

Como uma nova tentativa de fomentar o setor industrial brasileiro, a Política Industrial, Tecnológica e de Comércio Exterior (PITCE) foi lançada em 2004 com vistas ao aumento de produtividade e competitividade da estrutura produtiva nacional. A PITCE focava em quatro eixos: (i) inovação e desenvolvimento tecnológico; (ii) inserção externa via aumento das exportações de alta tecnologia; (iii) modernização industrial e ambiente institucional e (iv) aumento da capacidade produtiva (Coronel et al., 2014). Apesar de sua formulação adequada, a falta de articulação e coordenação inviabilizou a obtenção dos resultados pretendidos. Ademais, a proposição de ações mais horizontais que setoriais, a pouca ênfase nos instrumentos fiscais e, principalmente, a conjuntura econômica desfavorável ao lançamento de uma política industrial retiraram boa parte da eficácia das ações implantadas (Suzigan e Furtado, 2006).

Quanto à China, a política preferencial para atração de capital externo, iniciada em 1978 e intensificada a partir de 1992, tinha como objetivo a atração de empresas transnacionais. Uma vez instaladas em território chinês, as transnacionais deveriam associar-se às empresas locais, condicionadas a compromissos de transferência de tecnologia ou de abertura de centros de P\&D no país e aumento do desempenho exportador (formação de joint ventures) (Delgado, 2015). O governo chinês incentivou a instalação das joint ventures nas Zonas Econômicas Especiais (ZEEs) ${ }^{1}$, áreas com infraestrutura de energia e transporte e abundância de mão de obra. Aliado à política cambial de forte desvalorização real do renminbi, houve aumento do fluxo de IDEs e consequente formação de clusters industriais, principalmente de indústrias mais intensivas em conhecimento e tecnologia. Medidas de liberalização do comércio exterior chinês foram aceleradas ao final desta mesma década com vistas ao ingresso chinês na Organização Mundial do Comércio, efetivada em dezembro de 2001, o que aumentou a inserção chinesa no comércio internacional (Nonnenberg, 2010).

Dados os esforços governamentais do Brasil e da $\mathrm{China}^{2}$ para a construção de uma nova perspectiva de crescimento econômico interno aliado ao cresci-

1 As ZEEs criadas no litoral pelo governo chinês em 1980 e estendidas para o interior a partir da década de 1990.

2 A descrição das políticas de fomento à estrutura produtiva do Brasil e da China se ateve ao período proposto pela análise empírica - 1995-2005. Informações sobre políticas industriais recentes no Brasil e na China, consultar: Delgado et al. (2011); Araújo (2012); Coronel et al. (2014); Masiero e 
mento econômico mundial, criaram-se condições para uma mudança nos fluxos de comércio desses países. De acordo com os dados do Banco Mundial ${ }^{3}$, no período compreendido entre os anos de 1995 a 2005, as exportações brasileiras aumentaram 155\%, passando de US\$ 46.506 milhões para US\$ 118.529 milhões. Este desempenho favorável das exportações brasileiras reverteu o resultado comercial deficitário de US\$ 7.631 milhões em 1995 para um superávit na balança comercial de US\$ 40.901 milhões em 2005. Quanto à China, as exportações cresceram 402\% no mesmo período (de US\$ 148.780 milhões em 1995 para US\$ 761.953 milhões em 2005). Este resultado culminou em expressivo aumento da participação da China nas exportações mundiais, saltando de 2,88\% em 1995 para 7,55\% em 2005.

Diante do considerável crescimento das exportações do Brasil e da China, torna-se importante verificar se esse aumento da demanda externa possui a capacidade de propiciar o crescimento econômico sustentado nas referidas economias. Kaldor $(1966,1970)$ mostra que um rápido crescimento das exportações e da produção de produtos de média e alta tecnologias, de alta elasticidade-renda, capazes é capaz de fomentar um círculo virtuoso de crescimento no qual a expansão do produto gera expansão da produtividade (devido aos ganhos de escala) e esta, ao tornar o setor exportador mais competitivo, possibilita sua expansão. De acordo com o autor, a especialização da exportação em produtos baseados em recursos naturais não levaria ao desenvolvimento econômico por não se tratarem de bens intensivos em tecnologia e possuírem baixa elasticidade-renda e poucos encadeamentos intra e intersetoriais (Mccombie e Thirlwall, 1994). Em resumo, para Kaldor (1966, 1970), o conteúdo tecnológico dos bens presentes nas pautas de exportação e importação é fundamental para a viabilização do crescimento econômico sustentado.

Nesse contexto, a expansão das exportações e, em particular, dos setores de alta e média intensidades tecnológicas, possui um efeito multiplicador por toda a economia, gerando emprego e renda, além de estimular inversões sendo, portanto, fundamental para explicar o crescimento econômico. De outra forma, a expansão das exportações seria capaz de gerar renda nos próprios setores exportadores além de ter efeitos indiretos sobre a cadeia produtiva dos demais setores produtivos da economia. Ademais, as exportações seriam capazes de gerar renda adicional destinada ao consumo, retroalimentando a produção nacional de maneira que a economia entrasse em um círculo virtuoso de crescimento econômico.

Coelho (2014); Delgado (2015); Silva (2017) e outros.

3 Os dados podem ser consultados em: http://data.worldbank.org/topic/trade. 
Diante do exposto, este trabalho possui como objetivo analisar se o aumento das exportações brasileiras e chinesas no período de 1995 a 2005 possui capacidade de gerar crescimento econômico sustentado na lógica estruturalista-kaldoriana. Para alcançar o objetivo proposto, será utilizado um modelo de insumo-produto fechado para o setor externo (exportações e importações). O papel das exportações será verificado por meio do multiplicador simples de produção, índices de interligação e setores chave e pelo método de extração hipotético. A metodologia de insumo-produto possui aderência à análise estruturalista-kaldoriana, visto que permite verificar os encadeamentos e a importância do setor externo para os demais setores produtivos da economia. Como base de dados, serão utilizadas as matrizes de insumo-produto disponibilizadas pela OCDE com tecnologia setor x setor para os anos de 1995 e 2005 compatibilizada com base na taxonomia proposta por Lall (2000).

Além desta seção introdutória, o presente trabalho está estruturado como segue. A segunda seção descreve a importância do conteúdo tecnológico das exportações para o crescimento econômico. A terceira seção descreve a metodologia e a base de dados utilizadas. Já na quarta seção, são discutidos os resultados e, por fim, as considerações finais do estudo são empreendidas na quinta seção.

\section{O PAPEL DO CONTEÚDO TECNOLÓGICO DAS EXPORTAÇÕES PARA O CRESCIMENTO ECONÔMICO}

Kaldor (1966; 1970), com o objetivo de explicar os diferentes níveis de produto existentes entre os países, desenvolveu o modelo crescimento que ficou conhecido na literatura como modelo de crescimento kaldoriano. Uma das mais importantes conclusões do modelo kaldoriano é que as exportações, em particular as de produtos com alta elasticidade-renda, desempenham papel crucial no dinamismo das economias no longo prazo.

Na perspectiva kaldoriana, uma inserção externa dinamizadora mediante vantagens comparativas resultaria de um conjunto de medidas deliberadas pelo Estado para promover ações econômicas de caráter coletivo, expressos através de relações estabelecidas dentro de cadeias produtivas e em redes de empresas que favoreçam a criação ou a incorporação de novos paradigmas tecnológicos aos setores industriais. Dessa forma, a abordagem kaldoriana é, necessariamente, setor-específica e destaca o papel da indústria como elemento-chave em um processo de crescimento equilibrado. $\mathrm{O}$ setor industrial operaria com retornos crescentes de escala e seria capaz de induzir o ritmo da atividade econômica e crescimento da produtividade na estrutura produtiva como um todo (Pasinetti, 1983). 
Argumentos em defesa da importância da indústria para o crescimento econômico podem ser sintetizados no que a literatura convencionou chamar de "leis de Kaldor" (Kaldor, 1966; 1970). Estas leis apresentam os atributos inerentes à indústria de transformação que lhes conferem maior relevância para alavancar o crescimento dos demais setores produtivos e para disseminar ganhos de produtividade por toda a economia. De acordo com Kaldor $(1966 ; 1970)$, as referidas leis podem ser definidas do seguinte modo:

i) O crescimento da indústria e o crescimento do produto agregado apresentam relação positiva, sendo que os setores industriais mais dinâmicos e difusores de inovações seriam os propulsores do crescimento;

ii) Existe uma relação positiva entre o produto industrial e o crescimento da produtividade industrial. Essa lei, conhecida na literatura como lei de Kaldor-Verdoorn, postula que o aumento da produção, induzido pelo aumento da demanda, leva às economias de escala e, por conseguinte, à elevação da produtividade industrial nos quais esses ganhos de produtividade devem se refletir em aumento na competitividade da economia;

iii) Elevações na taxa de crescimento das exportações geram maior crescimento do produto e,

iv) No longo prazo, o crescimento da economia não seria restrito pela oferta, mas pela demanda. Nesse contexto, a principal restrição de demanda ao crescimento do produto de uma economia aberta seria o balanço de pagamentos.

A terceira e a quarta leis de Kaldor (1970) estão inter-relacionadas e foram formalizadas por Dixon e Thirlwall (1975) e Thirlwall (1979). A terceira lei indica que a demanda tem um papel central na explicação dos diferenciais de taxas de crescimento entre as economias, com ênfase na evolução das exportações como o principal componente da demanda final. Já a quarta lei postula que o crescimento pode ser inibido por restrições no balanço de pagamentos e, portanto, a sustentabilidade do crescimento depende da capacidade do país em manter a competitividade de suas exportações (Thirlwall, 1979; 1997; 2001).

Os estudos de Dixon e Thirlwall (1975), Thirlwall (1979) e Thirlwall (1983) concluem que as taxas de crescimento do produto e da produtividade da indústria são determinadas pela razão entre a taxa de crescimento das exportações e a elasticidade-renda da demanda por importações. Essa conclusão é denominada 
Lei de Thirlwall (Thirlwall, 1983). Nesse contexto, McCombie e Thirlwall (1994) destacam o desempenho do comércio exterior, particularmente das exportações, como crucial para o crescimento econômico sustentado livre de constrangimentos externos. Assim, o crescimento econômico sustentado do produto se daria por meio do equilíbrio no balanço de pagamentos.

Portanto, as exportações desempenhariam papel especial nos argumentos de Kaldor que permitem descrever o crescimento como um processo de causação circular cumulativo (Oliveira, 2011). Na visão de Kaldor e Thirlwall, o efeito das exportações sobre o crescimento do produto depende da estrutura produtiva de cada país. Segundo Kaldor e Mirrlees (1962), a introdução de máquinas e equipamentos mais intensivos em tecnologia é fundamental para determinar o ritmo de crescimento econômico.

Para McCombie e Roberts (2002), um aumento na taxa de crescimento das exportações possui dois efeitos sobre a renda: i) elevar a taxa de crescimento da renda através do multiplicador de comércio exterior de Harrod; ii) flexibiliza a restrição imposta pela condição de equilíbrio no balanço de pagamentos, permitindo o crescimento de outros componentes autônomos da demanda. A soma destes dois efeitos faz com que o super-multiplicador de Hicks aja na economia.

Por outro lado, se a economia não atingiu um nível de industrialização capaz de auferir os benefícios da causalidade cumulativa, os gestores de política econômica deveriam incentivar mudanças estruturais para alcançar tal padrão (Lamonica e Feijó, 2011). Assim, pressupõe-se que os estímulos da demanda sejam fortes o suficiente para, além de permitir os ganhos de escala pelo uso do estoque de capital existente, promoverem também a ampliação deste estoque com aquisição de máquinas e equipamentos mais modernos que, por definição, endogeinizam o progresso técnico (Feijó et al., 2013). Este progresso técnico ocorreria no sentido de aumentar a participação de setores mais intensivos em tecnologia, permitindo ganhos de competitividade não-preço, o que contribuiria para a diversificação na pauta de exportação da economia. Entretanto, a aquisição de máquinas e equipamentos deve levar em consideração a ressalva feita por Thirlwall e Hussain (1982). Para os autores, o nível de exportação deve ser o suficiente para cobrir as despesas adicionais com importações, pois caso isto não ocorresse, a economia teria uma restrição externa ao crescimento dada pela entrada de capitais e tornaria a economia vulnerável a choques externos.

Diante do exposto, é possível afirmar que os setores de alta e média intensidade tecnológica atuariam como indutores do crescimento, segundo a lógica kaldo- 
riana, por possuírem maior elasticidade-renda das exportações e, ainda, por serem os setores mais dinâmicos e difusores de inovações. Entretanto, conforme observado por Oliveira et al. (2006) e Jayme Jr e Resende (2009), a construção teórica kaldoriana argumenta implicitamente a importância do conteúdo tecnológico das exportações, dos processos de inovação e difusão tecnológica para o crescimento econômico. O progresso técnico e sua difusão em uma economia se verificam no contexto do desenvolvimento de um sistema nacional de inovação (SNI). O conceito de SNI corresponde a uma construção institucional que impulsiona o progresso tecnológico em economias capitalistas complexas, seja produto de uma ação planejada e consciente, seja de um somatório de decisões não planejadas e desarticuladas (Freeman, 1988; Nelson, 1993; Albuquerque, 1996).

Evidencia-se, portanto, que o desenvolvimento de um SNI possibilita maior sofisticação tecnológica à estrutura produtiva, o que se reflete em mudanças nas elasticidades-renda do comércio (maior elasticidade-renda da demanda por exportações e menor elasticidade-renda da demanda por importações) e, por conseguinte, na ruptura da restrição externa ao crescimento econômico sustentado (Missio e Jayme Jr, 2013). Nesse sentido, a ruptura da restrição externa no longo prazo, via aumento das exportações, seria alcançada por meio de um SNI desenvolvido que possui uma maior diversificação da base produtiva nacional (implicando em melhorias na competitividade não-preço) com impacto direto sobre as relações comerciais, uma vez que favorece a exportação de bens mais sofisticados tecnologicamente - de alta elasticidade-renda - e a importação de bens mais básicos - de baixa elasticidade-renda.

Os setores que atuam em segmentos de fronteira tecnológica, ou próximos a ela, viabilizariam o aumento do valor das suas exportações em decorrência de pelo menos três motivos, a saber: i) sua estrutura monopolizada ou oligopolizada; ii) alcançam os mercados externos dinâmicos (demanda externa crescente); e, iii) apresentam reduzida vulnerabilidade em relação ao grau de proteção comercial adotado pelos países. Dessa forma, quanto mais desenvolvido for o SNI, mais ampliada seria a estrutura produtiva e, assim, maiores seriam as "oportunidades tecnológicas" presentes nessa economia, e mais diversificada a pauta de exportações, favorecendo o aumento do valor da mesma por meio do seguinte: (i) da conquista de novos mercados; (ii) da estabilidade do crescimento do valor exportado; e (iii) do aumento da própria elasticidade-renda da demanda por exportações (Resende e Torres, 2008; Jayme Jr e Resende, 2009).

No longo prazo, o efeito sobre a economia seria a ruptura da restrição externa (balanço de pagamentos) ao crescimento configurando um círculo virtuoso, 
visto que ocorre a imbricação entre o progresso técnico, o padrão de comércio e o crescimento econômico conforme argumento kaldoriano. Nesse sentido, se do ponto de vista macroeconômico são os superávits comerciais que contam para o crescimento sustentado no longo prazo, do ponto de vista microeconômico é a intensidade tecnológica dos produtos comercializados que sustenta o resultado comercial positivo no longo prazo (Jayme Jr e Resende, 2009).

Diante da importância de um SNI maduro para o conteúdo tecnológico das exportações, Patel e Pavitt (1994) argumentam que deveria ser adotada uma estratégia de longo prazo (dinâmica) para a formação do SNI, onde os investimentos tecnológicos receberiam um tratamento privilegiado na economia nacional levando em consideração os seus efeitos benéficos, tais como os processos de aprendizado tecnológico, organizacional e mercadológico.

Por outro lado, a formação de um SNI incipiente pode ser devida à adoção de uma estratégia curto-prazista (míope) na qual os investimentos tecnológicos seriam equiparados a quaisquer outros tipos de investimento (Patel e Pavitt, 1994). Nesse caso, um SNI incompleto poderia gerar uma balança comercial deficitária, haja visto que seria pautada por importações de maior conteúdo tecnológico (elasticidade-renda alta) e exportações de baixo teor tecnológico, essencialmente commodities (baixa elasticidade-renda) o que, no longo prazo, resultaria em restrição do balanço de pagamentos ao crescimento. Além disso, o país estaria mais exposto ao problema da deterioração dos termos de troca, tornando-se vulnerável a mudanças no cenário externo, perpetuando, por conseguinte, o subdesenvolvimento de sua economia (Prebisch, 1950; Singer, 1950). Nessa mesma perspectiva, Kaldor (1966) argumenta que tais círculos viciosos de crescimento surgiriam devido à incapacidade de se obter rendimentos de escala dinâmicos e efeito multiplicador do comércio que inibem a ampliação da demanda por exportações e da produção no longo prazo.

\section{ASPECTOS METODOLÓGICOS E BASE DE DADOS}

II.1. Modelo fechado de insumo-produto e o multiplicador simples de produção, índices de interligação e setores chave

A estrutura analítica matricial do modelo de insumo-produto, desenvolvida por Leontief (1941), fornece a descrição completa das interdependências ou interações (sobre a ótica de compra e venda) dos setores produtivos em um determinado tempo e localidade (nação, região, estado) (Miller e Blair, 2009). Esse 
modelo parte da hipótese de equilíbrio na qual a quantidade demandada é idêntica à quantidade produzida de bens e serviços. Ademais, esse modelo detém limitações, como: (i) coeficiente tecnológico constante, (ii) retornos constantes de escala, (iii) demanda final definida exogenamente e (iv) preços rígidos.

Os fluxos intersetoriais de bens e serviços de uma economia com $n$ setores, determinados por fatores tecnológicos e econômicos, podem ser representados matricialmente da seguinte forma (Leontief, 1965):

$$
X=A * X+Y
$$

Onde $X=$ vetor $(N x 1)$ do valor bruto da produção; $Y=$ vetor $(N x 1)$ de demanda final setorial; $A=$ matriz $(N x N)$ de coeficientes técnicos de produção ${ }^{4}$;

A construção da matriz $A$ é feita a partir da relação fixa entre a produção de um setor e os seus insumos $\left(z_{i j} / x_{j}\right)$, isto é, os coeficientes técnicos $\left(a_{i j}\right)$. Onde $z_{i j}=$ fluxo de insumos intermediários do setor $i$ para o setor $j$ e $x_{j}=$ valor bruto da produção do setor $j$;

Rearranjando a equação (1) em função de $Y$ (demanda final), chega-se a:

$$
X=B Y
$$

Em que $B=(I-A)^{-1}$ é uma matriz $(N \mathrm{x} N)$ conhecida como matriz inversa de Leontief ou matriz de coeficientes diretos e indiretos. I é uma matriz identidade $(N x N)$.

No modelo, com o vetor de demanda final setorial conhecido e fixo, pode-se determinar o vetor de produção total setorial por meio da equação matricial chave do modelo de insumo-produto regional. Esta equação chave do modelo de insumo-produto básico de Leontief é classificada como de tecnologia baseada na indústria e com enfoque setor $\mathrm{x}$ setor. Neste trabalho, os setores da economia estão agregados em seis setores produtivos, a saber: i) setores de alta intensidade tecnológica; ii) setores de média intensidade tecnológica; iii) setores de baixa intensidade tecnológica; iv) setores intensivos em trabalho e recursos naturais; v) commodities e vi) setores baseados em serviços. Cabe ressaltar que os seis setores produtivos utilizados na análise empírica serão detalhados de forma pormenorizada na seção 3.3.

4 A matriz $A$ também é conhecida como matriz de coeficientes diretos. 
De modo a fechar o modelo descrito na Equação (2) para o setor externo (exportações e importações), deve-se criar uma nova coluna e uma nova linha no consumo intermediário. A nova coluna é composta pelo vetor de exportações $(E)$, extraída do vetor de demanda final $(Y)$, enquanto a linha adicional contempla o vetor de importações setoriais $(M)$, extraída da matriz de insumos primários. Dessa forma, a matriz $B$ passa a ter a dimensão $7 \times 7$ e as exportações e as importações tornam-se endógenas ao modelo, uma vez que passam a ser componentes do consumo intermediário. Dessa forma, a equação-chave do modelo passa a ser:

$$
X^{f}=B^{f} Y^{f}
$$

Onde: $X^{f}$ denota o VBP dos seis setores da economia adicionado do "setor" externo (exportações e importações); $B^{f}$ denota a matriz de coeficientes diretos, indiretos e induzidos dos seis setores da economia mais o "setor" externo e $Y^{f}$ é o vetor de demanda final deduzido o vetor das exportações $(E)$. Vale ressaltar que, após implementado o fechamento do modelo (Equação 3), os cálculos para a obtenção da equação-chave do modelo de insumo-produto fechado para o setor externo podem ser facilmente realizados de maneira análoga ao anteriormente demonstrado.

A partir da Equação (3) é possível empregar a análise dos multiplicadores básicos de insumo-produto. Os multiplicadores complementam a análise da importância de determinado setor na economia, pois permitem avaliar os impactos resultantes de choques exógenos sobre determinado sistema econômico (Rodrigues et al., 2007). Os multiplicadores mais utilizados são aqueles que simulam e estimam os efeitos de uma mudança exógena na demanda final.

O multiplicador de produção para cada setor é a soma da sua respectiva coluna na matriz inversa de Leontief $\left(B^{f}\right)$. Ele corresponde a uma variação direta, indireta e induzida da produção total da economia de todos os setores e regiões decorrente da variação exógena de uma unidade monetária da demanda final de determinado setor de uma região (Miller e Blair, 2009). Assim, o multiplicador do produto para o setor $j$ é definido como o valor total da produção adicional em todos os setores da economia, que é necessário para satisfazer a uma unidade monetária adicional da demanda final do produto do setor $j$. Em termos formais, o multiplicador de produção simples para o setor $j, O j$, será dado por:

$$
O_{j}=\sum_{i=1}^{7} b_{j}^{f}
$$


onde: $j$ é um determinado setor da economia; $b_{i j}^{f}$ representa os elementos da matriz inversa de Leontief para o modelo fechado para o setor externo.

A ideia de dependência setorial, encadeamentos setoriais e interdependência regional são tratadas pela literatura de insumo-produto de várias formas. Rasmussen (1952) e Hirschman (1958) utilizam os índices de ligação para trás e para frente para estabelecer os setores que teriam o maior poder de encadeamento dentro da economia. Os linkages para trás (poder de dispersão) - $U_{j}$ - determinam o quanto um setor demanda dos demais setores da economia e os linkages para frente (sensibilidade da dispersão) $-U_{i}-$ determinam o quanto este setor é demandado pelos demais setores da economia.

Para o cálculo dos efeitos de encadeamento para trás e para frente, deve-se utilizar a matriz inversa de Leontief fechada para o setor externo $-B^{f}=\left(I-A^{f}\right)^{-1}-$ de forma que os índices são computados da seguinte forma:

Índice de ligação para trás:

$$
U_{j}=\frac{b_{{ }_{j}} / 7}{B^{*}}
$$

onde: $B_{i j}$ - cada elemento da matriz $B^{f}$, sendo $i$ as linhas e $j$ as colunas; $b_{.}{ }_{j}$ - soma das colunas de $B f ;$ - corresponde à soma total da matriz $B f_{;}, b_{. j} / 7$ é o valor médio dos elementos na linha $i$ e, $B^{*}$-valor médio de todos os elementos de $B^{f}$, ou seja,

$$
B^{*}=\frac{b .}{n^{2}}
$$

O índice de ligação para frente é formalizado como segue:

$$
U_{i}=\frac{b_{i} \cdot / 7}{B^{*}}
$$

onde: $b_{i} \cdot-$ soma das linhas de $B{ }^{f} ;{ }_{i} \cdot / 7$ corresponde ao valor médio dos elementos na coluna $j$.

O índice de ligação para trás $\left(U_{j}\right)$ determina o quanto um setor compra dos demais setores da economia. Se este índice for superior à unidade, isto significa que, quando há uma variação na demanda final do setor $j$, o mesmo gera uma 
compra de insumos acima da média na economia, revelando fortes encadeamentos para trás no sistema produtivo.

Já o índice de ligação para frente $\left(U_{i}\right)$ descreve o quanto o setor $i$ vende para o restante da economia. Se $U_{i}>1$, significa dizer que a produção do setor $i$ aumenta acima da média na economia decorrente de uma variação na demanda final. Tal fato aponta que os demais setores da economia possuem uma dependência acima da média da produção do setor $i$, uma vez que o setor $i$ se destaca como forte fornecedor de insumos (encadeamentos para frente) para a economia da região.

Se um determinado setor apresentar valores de $U_{j}$ e $U_{i}$ superiores à unidade, isto significa que ele é considerado setor-chave na economia de uma determinada região, visto que provoca um efeito de encadeamento de compra e venda acima da média.

\section{II.2. Método de Extração Hipotética}

O método de extração hipotética proposto por Dietzenbacher et al. (1993) aplicado à matriz de insumo-produto busca identificar setores estrategicamente importantes para o desenvolvimento econômico complementando a análise de interligação para frente, para trás e setores-chave proposta por Hirschman (1958). Visto que um choque em um setor, considerado estratégico na economia, possui um poder de influenciar a produção de outros setores produtivos, a detecção destes setores é importante em termos de formulação de política econômica.

A ideia do método de extração consiste, portanto, na extração hipotética e/ ou imaginária de um determinado setor da estrutura de insumo-produto. $\mathrm{O}$ objetivo deste método é quantificar quanto da produção total de uma economia de $n$ setores reduziria se um setor específico, dito $j$-ésimo setor, fosse removido da economia. No presente trabalho, isto foi modelado em um contexto de insumo-produto fechado atribuindo zero à linha e à coluna $j$ da matriz $A^{f}$, sendo $j$ o setor externo ${ }^{5}$. Utilizando $\bar{A}_{(j)}^{f}$ para denotar a matriz sem o setor $j$ de dimensão $(n-1) x(n-1)$ e considerando que $\bar{Y}_{(j)}^{f}$ corresponde ao vetor de demanda final deduzido o setor externo, a equação chave do modelo de insumo-produto passa a ser:

$$
\bar{X}_{(j)}^{f}=\left(I-\bar{A}^{f}(j)\right)^{-1} \bar{X}_{(j)}^{f}
$$

5 Uma forma alternativa de extrair hipoteticamente um setor é eliminar a linha e a coluna do $j$-ésimo setor na matriz de coeficientes técnicos $-A$ (Miller e Blair, 2009, p. 563). 
Uma medida agregada da perda da economia (redução do VBP) caso o setor $j$ seja extraído, pode ser definida como a diferença entre o VBP considerando o setor externo (equação 10) e o VBP após a extração do referido setor (Equação 8). Em termos formais:

$$
T_{j}=i^{\prime} X^{f}-i^{\prime} \bar{X}_{(j)}^{f}
$$

Onde $i$ 'é um vetor coluna transposto de dimensão $1 \times 7$.

$T_{j}$ pode ser interpretado como uma medida dos linkages totais do setor externo $(j)$, afinal a Equação (9) calcula o efeito total da extração do setor externo demonstrando a sua importância para a economia como um todo. Vale apontar que quanto maior o valor de $T_{j}$, maior a interdependência do setor externo com os setores produtivos da economia analisada, logo, maior a importância do setor externo para o dinamismo do crescimento da referida economia.

A Equação (9) pode ser dividida pelo VBP original $\left(i^{\prime} x^{f}\right)$ e multiplicada por 100 de modo a fornecer uma medida agregada da perda da economia em termos percentuais:

$$
\bar{T}_{j}=\left[\frac{\left(i^{\prime} X^{f}-i^{\prime} \bar{X}_{(j)}^{f}\right)}{i^{\prime} X^{f}}\right] 100
$$

Uma forma alternativa de calcular a importância do setor externo para os demais setores da economia como um todo pode ser computada da seguinte forma:

$$
T_{j}^{(A)}=\left[\left(i^{\prime} X^{f}-x_{J}\right)-i^{\prime} \bar{X}_{(j)}^{f}\right]
$$

Onde $x_{j}$ se refere ao VBP do setor externo.

Analogamente à Equação (10), pode-se calcular a perda agregada percentual da seguinte maneira:

$$
T_{j}^{(A)}=\left[\frac{\left(i^{\prime} X^{f}-x_{J}\right)-i^{\prime} \bar{X}_{(j)}^{f}}{i^{\prime} X^{f}}\right] 100
$$

A abordagem de extração hipotética também é capaz de mensurar separadamente os linkages para frente e para trás do setor extraído. O cômputo desses linkages é importante para verificar a dependência em termos de compra e venda dos demais setores da economia no contexto hipotético de inexistência do setor 
externo. Pelo fato de o presente trabalho pretender analisar a hipótese kaldoriana, serão computados somente os linkages para trás, afinal estes conseguem verificar a dependência dos setores dessas economias em relação à exportação. Em outros termos, os linkages para trás são capazes de verificar se a produção das economias brasileira e chinesa voltada para o setor externo está concentrada nos setores de maior intensidade tecnológica.

Visando calcular o poder de dispersão ou arrasto das exportações para as economias brasileira e chinesa (dependência pela ótica das compras), deve-se assumir que a coluna do setor externo na matriz de coeficientes técnicos $\left(\bar{A}_{(j)}^{f}\right)$ seja igual a zero. Posto de outra forma, de modo a verificar a importância da interdependência do setor externo com os demais setores da economia, pressupõe-se, de maneira hipotética, que o setor externo não compra insumos de quaisquer setores produtivos, isto é, que não existem linkages para trás do setor externo.

Após assumir que $\bar{A}_{(j)}^{f}=0$, a nova matriz de coeficientes técnicos passa a ser denotada por . A partir de então a Equação chave do modelo de insumo-produto toma a seguinte forma:

$$
\bar{X}_{(c j)}^{f}=\left(I-\bar{A}_{(c j)}^{f}\right)^{-1} \bar{Y}^{f}
$$

A medida agregada da importância das exportações para a economia como um todo, ou seja, a dependência para trás do setor externo, pode ser calculada por meio da diferença do VBP original e o VBP desconsiderando os linkages para trás do setor externo. Formalmente:

$$
B L_{j}=i^{\prime} X^{f}-i^{\prime} \bar{X}_{(c j)}^{f}
$$

Além do cálculo de uma medida agregada da importância das exportações para o dinamismo da economia, é interessante, para o propósito do presente trabalho, mensurar a dependência para trás do setor externo sobre cada um dos demais setores da economia. Essa medida pode ser mensurada como segue:

$$
B L_{j}^{i}=X^{f}-\bar{X}_{(c j)}^{f}
$$

Por intermédio da equação (15) é possível verificar quais setores são mais dependentes das exportações para a dinâmica do seu crescimento.

Uma medida por unidade de produto pode ser computada por meio de uma normalização da seguinte forma: 


$$
\overline{B L}_{j}^{i}=\frac{\left(x_{i}^{f}-x_{(c j) i}^{f}\right)}{x_{j}}
$$

Em síntese, se os setores mais afetados pela extração do setor externo forem os setores de alta e média intensidade tecnológica, esta economia terá um círculo virtuoso e sustentado de crescimento econômico de acordo com a lógica estruturalista-kaldoriana. Do contrário, se os impactos mais expressivos forem concentrados nos setores de baixa intensidade tecnológica, intensivos em trabalho e recursos naturais e commodities, a economia analisada estaria predestinada a manter o seu subdesenvolvimento.

\section{II.3. Base de dados}

Este trabalho utiliza como base de dados as matrizes de insumo-produto (MIP) regional do Brasil e da China, para os anos de 1995 e 2005, disponibilizadas pela Organização para a Cooperação e Desenvolvimento Econômico (OCDE). As MIPs da OCDE estão dispostas com uma agregação de 48 setores produtivos com tecnologia setor $\mathrm{x}$ setor, sendo 3 setores primários, 22 setores industriais e 23 setores de serviços. Em consonância com o Sistema de Contas Nacionais de 2008 (SNA2008), as transações nestas MIPs são mensuradas a preços básicos. A classificação setorial das MIPs da OCDE é baseada na classificação internacional de atividades econômicas (ISIC) ${ }^{6}$. Conforme apontado por Yamano e Ahmad (2006, p. 11), as MIPs de 1995, baseadas na versão anterior do sistema ISIC Revisão 2, são amplamente comparáveis às MIPs de 2005, baseadas na ISIC Revisão 3, ao nível setorial apresentado.

Visando verificar a importância do conteúdo tecnológico dos setores produtivos das economias brasileira e chinesa no que tange às exportações, uma compatibilização dos setores das MIPs em relação ao conteúdo tecnológico foi realizada estendendo a taxonomia proposta por Lall (2000) para todos os setores da economia 7 . Dessa forma, as MIPs com 48 setores, disponibilizadas pela OCDE, foram agregadas de modo que as MIPs compatibilizadas passam a ter 6 setores produtivos, a saber: i) setores de alta intensidade tecnológica que consideram os

6 ISIC é o acrônimo de International Standard Industrial Classification.

7 Para se adequar à formatação exigida, maiores detalhes sobre a agregação dos setores das MIPs disponibilizadas pela OCDE baseadas na taxonomia de Lall (2000) não puderam ser apresentadas. Os autores informam que a compatibilização bem como as matrizes compatibilizadas poderão ser disponibilizadas mediante solicitação. 
setores demandantes de mão-de-obra mais qualificada e exigem maior intensidade de tecnologia, escala e capital, tais como produtos eletrônicos, farmacêuticos e de informática; ii) setores de média intensidade tecnológica abrangendo os eletrodomésticos e automóveis, entre outros; iii) setores de baixa intensidade tecnológica que contemplam itens de ferro e aço, produtos de metal e suas obras; iv) setores intensivos em trabalho e recursos naturais, tais como têxteis, vestuário e calçados; v) commodities que compreendem os setores relativos às commodities primárias, além de pecuária e pesca; e vi) setores baseados em serviços agregam os demais produtos que não se enquadram em nenhuma das cinco categorias acima como, por exemplo, eletricidade, comércio e os serviços de forma geral.

\section{ANÁLISE E DISCUSSÃO DOS RESULTADOS}

Do ponto de vista estruturalista-kaldoriano, o conteúdo tecnológico e a elasticidade-renda dos bens presentes nas pautas de exportação e importação são fundamentais para a viabilização do crescimento no longo prazo. Nesse sentido, esta abordagem enfatiza que alterações nas elasticidades-renda das exportações e importações estão associadas a mudanças na estrutura produtiva impactando os ganhos comerciais e o crescimento econômico. Na lógica kaldoriana, um rápido crescimento das exportações e da produção de produtos de média e alta tecnologias, de alta elasticidade-renda, são capazes de fomentar um círculo virtuoso de crescimento econômico. De forma complementar, a literatura neo-schumpeteriana considera que o desenvolvimento tecnológico é o elemento propulsor do crescimento sustentado. Assim, enquanto os superávits comerciais são importantes para o crescimento de longo prazo pela ótica macroeconômica, a intensidade tecnológica dos produtos comercializados, derivada da ótica microeconômica, sustentaria o resultado comercial positivo com o passar do tempo.

Diante disso, o modelo de insumo-produto fechado para o setor externo permite verificar se a mudança estrutural ocorrida nas balanças comerciais do Brasil e da China entre os anos de 1995 e 2005 possui a capacidade de propiciar o crescimento econômico sustentado dessas economias. Os indicadores de insumo-produto são capazes de averiguar a interdependência do setor externo com os demais setores da economia, além de verificar se o conteúdo tecnológico presente nos setores exportadores segue a lógica estruturalista-kaldoriana.

Nesse contexto, uma maneira de avaliar a importância das exportações para as economias brasileira e chinesa seria por meio da análise da interdependência do setor externo com os demais setores produtivos. Essas interligações, a montante e 
a jusante das atividades produtivas, podem ser avaliadas através dos índices desenvolvidos por Rasmussen (1956) e Hirschman (1958). Os resultados desses índices de interligação estão reportados nas Tabelas 1 e 2 (colunas 2 a 7) para os anos de 1995 e 2005, respectivamente.

Por meio da análise das colunas 2 e 3 das Tabelas 1 e 2, nota-se que os setores com poder de dispersão acima da média, tanto para o Brasil quanto para a China, foram os de média e alta intensidades tecnológicas e o setor externo para ambos os anos. Ou seja, os referidos setores mostraram-se capazes de induzir a atividade produtiva nacional, uma vez que estes setores demandam insumos acima da média dos demais setores da economia. O poder de dispersão acima da média do setor externo merece destaque, tendo em vista que este resultado revela a importância do setor externo na estratégia de crescimento de ambas as economias.

Quanto aos setores com fortes encadeamentos para frente (colunas 4 e 5 das Tabelas 1 e 2), podem ser citados os de média intensidade tecnológica e baseados em serviços para Brasil e China em ambos os anos analisados. Esse resultado mostra que tais setores são demandados acima da média pelos demais setores da economia. Cabe observar que o setor intensivo em trabalho e recursos naturais também possui linkages para frente para o Brasil nos anos de 1995 e 2005. Esse resultado pode ser um indício de um SNI incompleto, uma vez que o referido setor não necessita de mão de obra qualificada tampouco de recursos tecnológicos para promover sua atividade produtiva. 


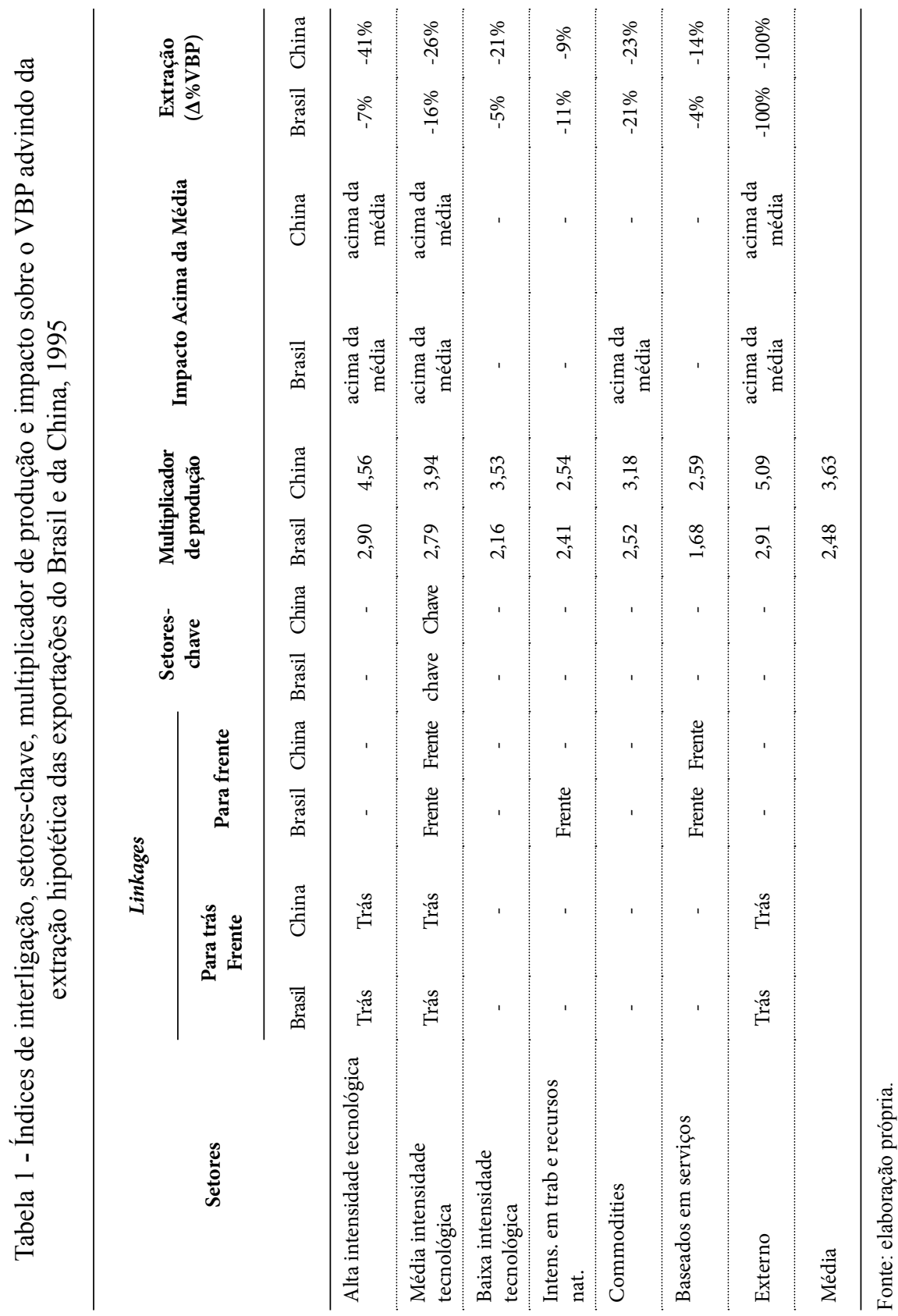


ANÁLISE DAS EXPORTAÇÕES NA LÓGICA ESTRUTURALISTA-KALDORIANA: ...

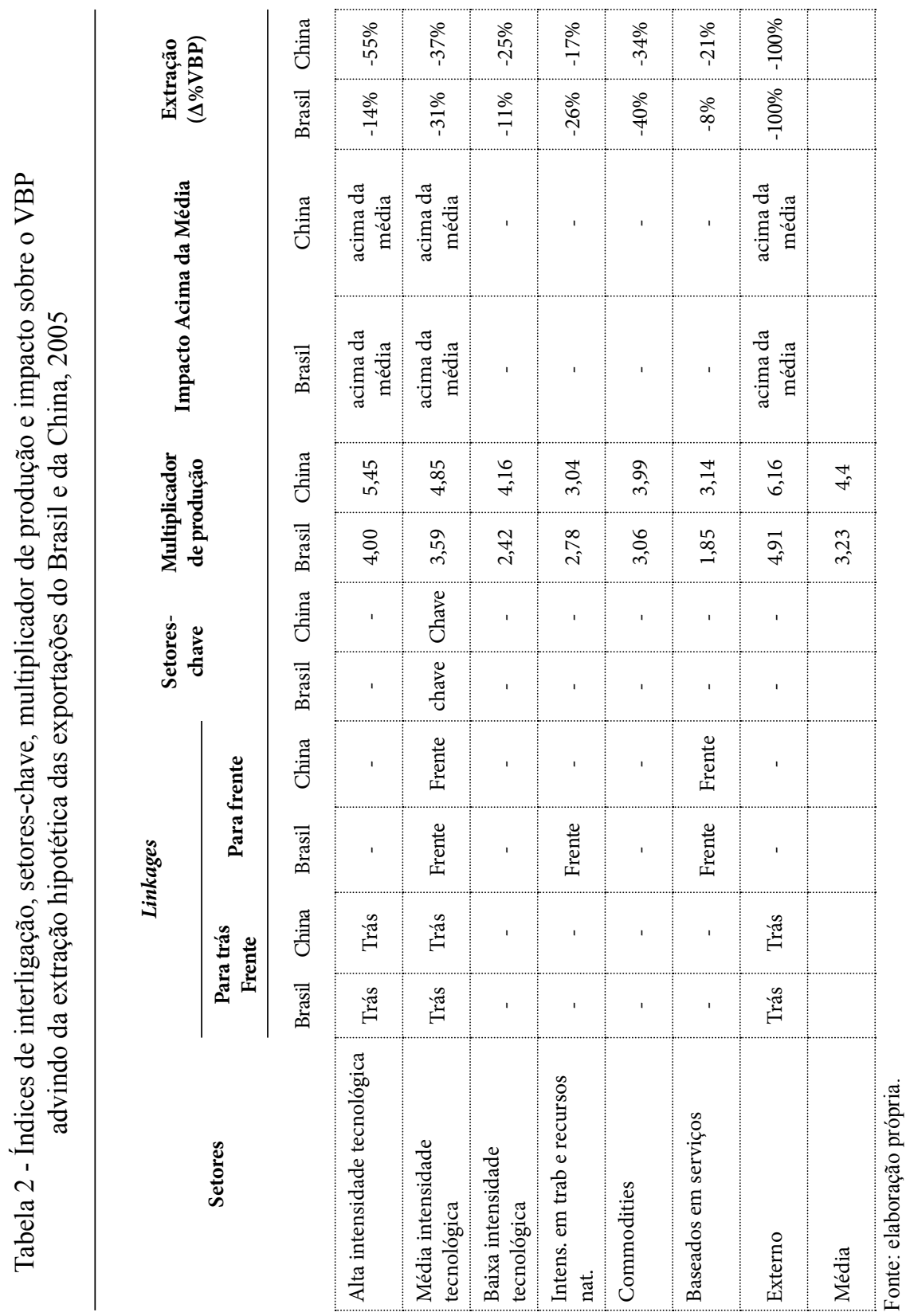


Tendo em vista que o setor de média intensidade tecnológica possui encadeamentos para frente e para trás acima da média, o mesmo pode ser considerado como setor-chave tanto para o Brasil quanto para a China nos anos analisados. De acordo com a análise de Rasmussen (1956) e Hirschman (1958), os esforços de investimento deveriam ser concentrados neste setor como uma estratégia de crescimento dessas economias, afinal o setor de média intensidade tecnológica possui a capacidade de alavancar a estrutura produtiva destes países. Entretanto, na perspectiva estruturalista-kaldoriana, os setores estratégicos para a dinamização das economias seriam os setores de alta e de média intensidade tecnológica, uma vez que estes setores seriam capazes de propiciar o crescimento sustentado das economias. Pelo fato de o setor de alta intensidade tecnológica não ter se apresentado como um setor-chave parece que o SNI de ambas as economias está incompleto.

Conforme apontado por Palermo et al. (2010), embora os índices de interligações de Rasmussen-Hirschman permitam diagnosticar os setores com maior interdependência na estrutura produtiva da economia, os multiplicadores de produção complementam a análise da importância de determinado setor na economia, pois permitem avaliar os impactos diretos, indiretos e induzidos sobre a cadeia produtiva analisada advindos da variação da demanda final. Vale observar que a média do multiplicador de produção da China é superior à do Brasil nos dois anos analisados (colunas 8 a 11 das Tabelas 1 e 2, respectivamente) evidenciando que a estrutura produtiva da economia chinesa possui maior capacidade de gerar renda adicional internamente em decorrência de variações na demanda final. Os setores que gerariam impacto acima da média no produto das economias do Brasil e da China seriam os de alta e média intensidades tecnológicas além do setor externo nos anos de 1995 e 2005.

Esses resultados corroboram a lógica kaldoriana de crescimento econômico, uma vez que variações na demanda final destes setores mais intensivos em tecnologia aumentariam o produto acima da média tanto do Brasil quanto da China em ambos os anos analisados. Em se tratando especificamente do setor externo, pode-se inferir que o mesmo possui a capacidade de alavancar a produção dos demais setores para ambas as economias sugerindo que os esforços dos governos brasileiro e chinês para a inserção no comércio internacional surtiram efeito. Um resultado que poderia ser considerado contrário à lógica kaldoriana seria o multiplicador de produção acima da média do setor commodities no ano de 1995 para o Brasil, demonstrando que a economia brasileira possuiria uma vocação à produção de commodities no ano em questão. Entretanto, vale apontar que, no decorrer de uma década, o referido setor perde importância na estrutura produtiva brasileira, deixando de possuir um multiplicador de produção acima da média no ano de 2005. 
No que se refere à importância do setor externo para o dinamismo econômico do Brasil e da China, a extração hipotética realizada mostra que a economia chinesa é mais dependente do setor externo em comparação à economia brasileira. Esse fato pode ser comprovado por intermédio do resultado da perda agregada da economia do Brasil e da China, caso esses países fossem economias fechadas ao setor externo: enquanto no Brasil o VBP reduziria 13\% em 1995 e $22 \%$ em 2005, na China a redução do VBP em 1995 seria da ordem de 19\% e de 35\% em 2005. Estes resultados mostram que, apesar de o Brasil ter aumentado sua inserção no comércio internacional, a China estreitou ainda mais suas relações comerciais com a economia mundial. Portanto, as políticas de inserção no comércio internacional de ambas as economias parecem, de fato, ter sido exitosas no decorrer da década analisada.

Quanto ao conteúdo tecnológico dos setores exportadores (colunas 12 e 13 das Tabelas 1 e 2), o cálculo dos linkages para trás da extração hipotética do setor externo permite verificar quais setores seriam mais prejudicados caso as exportações fossem inexistentes. Em outros termos, o cômputo dos linkages para trás das exportações possibilita a identificação dos setores estrategicamente importantes para o crescimento econômico dos países na lógica kaldoriana.

No caso do Brasil, o setor mais prejudicado com a ausência hipotética das exportações no ano de 1995 seria o setor commodities, uma vez que a redução do seu produto seria da ordem de $21 \%$ (coluna 12 da Tabela 1). No ano de 2005, a situação assemelha-se com o período anterior, afinal o setor commodities continuaria sendo o mais impactado reduzindo seu produto em $40 \%$ (coluna 12 da Tabela 2). No mesmo sentido, o setor de média intensidade tecnológica também passaria a ser mais dependente das exportações entre os anos de 1995 e 2005. Sendo assim, a perda de produto por ocasião da ausência das exportações para o referido setor, que em 1995 seria no montante de 16\% (coluna 12 da Tabela 1), passaria para $31 \%$ em 2005 (coluna 12 da Tabela 2). O setor intensivo em trabalho e recursos naturais também seria consideravelmente impactado, afinal sua produção reduziria $11 \% \mathrm{em}$ 1995 e $26 \%$ em 2005.

Diante desses resultados, a pauta de exportação brasileira na década considerada por este estudo parece ter se concentrado em produtos de baixo teor tecnológico, cuja elasticidade-renda é baixa. Por outro lado, as importações seriam pautadas por produtos de maior conteúdo tecnológico (elasticidade-renda alta). Sendo assim, a balança comercial tenderia a um déficit, o que, no longo prazo, resultaria em restrição externa do balanço de pagamentos, inviabilizando o cres- 
cimento sustentado da economia segundo argumento kaldoriano. Este resultado pode ser reflexo direto da falta de articulação e coordenação das políticas industriais brasileiras adotadas no período analisado. As políticas não foram capazes de endogeinizar o progresso técnico na estrutura produtiva brasileira, resultando em um SNI frágil e incompleto incapaz de impulsionar a diversificação da base produtiva nacional de modo a dinamizar a exportação de bens mais sofisticados tecnologicamente e com alta elasticidade-renda.

Desta forma, os resultados acerca do papel do conteúdo tecnológico das exportações brasileiras para garantir o crescimento sustentado da economia, segundo argumento kaldoriano, mostram-se preocupantes sob o prisma de três possíveis desvantagens decorrentes do tipo de especialização comercial encontrado: (i) os mercados internacionais de commodities e produtos intensivos em trabalho e recursos naturais são menos dinâmicos do que os de produtos mais sofisticados tecnologicamente; (ii) devido ao fato de os produtores de commodities e produtos intensivos em trabalho e recursos naturais serem, majoritariamente, price takers, os preços desses bens estão mais suscetíveis às variações em relação aos preços de produtos mais intensivos em tecnologia, aumentando o grau de incerteza a respeito da evolução das receitas desses produtores com implicações negativas sobre o investimento e, (iii) commodities e produtos intensivos em trabalho e recursos naturais estão mais sujeitos a práticas anticomerciais (protecionistas), sobretudo em países desenvolvidos.

No que tange ao conteúdo tecnológico das exportações chinesas, é possível perceber que o setor de alta intensidade tecnológica seria o setor mais impactado já em 1995, com uma redução de 41\% no seu VBP (coluna 13 das Tabela 1). Em 2005, mais da metade da produção do setor de alta intensidade tecnológica foi destinada ao comércio internacional, afinal a redução do VBP deste setor em 2005, considerando a situação hipotética de inexistência das exportações, seria de 55\% (coluna 13 das Tabela 2). Outro resultado interessante refere-se ao setor de média intensidade tecnológica, o segundo setor mais impactado pela situação hipotética de ausência de exportações: em 1995 esse setor reduziria 26\% de seu VBP, enquanto em 2005 a redução seria da ordem de 37\%. Diante desses resultados, tornam-se factíveis superávits comerciais crescentes, tendo em vista que a pauta de exportação chinesa concentrou-se em produtos de alta elasticidade-renda, permitindo ganhos de competitividade não-preço. Em virtude do alto conteúdo tecnológico das exportações chinesas, a restrição externa do balanço de pagamentos seria rompida, possibilitando o crescimento econômico sustentado nos moldes da lógica estruturalista-kaldoriana. 
Diante dos resultados encontrados, é possível inferir que a estratégia de fortalecimento da indústria chinesa via joint ventures instaladas nas ZEEs foi bem-sucedida consolidando uma estrutura produtiva baseada em conhecimento e tecnologia e inovação o que foi capaz de desenvolver o SNI do país. Portanto, a política industrial planejada adotada pelo governo conseguiu inserir a economia da China no comércio internacional através da exportação de bens intensivos em tecnologia e com alta elasticidade-renda e da importação de bens de baixa tecnologia, promovendo o catch up tecnológico chinês nos anos recentes. O amadurecimento do SNI chinês pode ser entendido pelo fato de a indústria chinesa ter avançado ao longo da cadeia global de valor, elevando seu valor agregado e o conteúdo tecnológico de suas exportações de maneira contínua (Nonnenberg, 2010).

\section{CONSIDERAÇÕES FINAIS E IMPLICAÇÕES POLÍTICAS}

A partir da década de 1990, os governos brasileiro e chinês promoveram políticas e incentivos para aumentar a competitividade de suas estruturas produtivas, visando a inserção no comércio internacional como uma das estratégias de crescimento econômico. Dada a melhora da balança comercial observada entre os anos de 1995 e 2005, fez-se necessário o entendimento do conteúdo tecnológico das exportações do Brasil e da China de modo a verificar se a expansão das exportações teria capacidade de arrasto do crescimento econômico sustentado, seguindo a lógica estruturalista-kaldoriana.

Diante dos resultados obtidos por este estudo, os setores chineses mais dependentes da exportação em relação ao aumento de seu produto seriam os setores de alta e média intensidade tecnológica. A China passou por uma reestruturação do padrão de comércio via incremento tecnológico de suas exportações vis-à-vis uma redução gradual das exportações de baixo valor agregado, resultando em maior dinamismo econômico e industrial. Esta estratégia permitiu a China aumentar sua participação nas cadeias globais de valor, tornando-se um dos principais players no comércio global. Assim, é possível concluir que a política preferencial para atração de capital externo iniciada em 1978 e intensificada a partir de 1992, a formação de joint ventures e a criação das ZEEs, a política de desvalorização do renminbi e os baixos custos da mão de obra impulsionaram o aumento do fluxo de IDEs e consequente formação de clusters industriais, principalmente de indústrias mais intensivas em conhecimento e tecnologia. Assim, é possível afirmar que a construção institucional planejada e consciente do Estado foi capaz de construir as bases de um SNI desenvolvido na China. 
Portanto, o fomento às atividades de $\mathrm{P} \& \mathrm{D}$, à captação de IDEs e o desenvolvimento de capital humano possibilitou à China se beneficiar dos setores de maiores oportunidades tecnológicas que possuem um esforço inovador maior e, por conseguinte, criar condições para sustentar seu crescimento econômico. Neste sentido, a economia chinesa teria promovido a ruptura da restrição externa do balanço de pagamentos, em decorrência da alta elasticidade-renda de suas exportações, configurando um círculo virtuoso dado que ocorre a imbricação entre o progresso técnico, o padrão de comércio e o crescimento econômico conforme argumento kaldoriano.

No caso da economia brasileira, os setores mais dependentes da exportação em relação ao aumento de seu produto, decorrentes da extração hipotética do setor externo, foram os setores de commodities de média intensidade tecnológica e intensivos em trabalho e recursos naturais. Estes achados se mostram preocupantes visto que estes produtos de baixa intensidade tecnológica e baixa elasticidade-renda aumentaram sua participação no comércio internacional ao longo da década analisada (1995-2005). Pode-se afirmar que a economia brasileira não conseguirá realizar inversões permanentes na balança comercial, uma vez que, no longo prazo, a baixa intensidade tecnológica da pauta de exportação frente ao fluxo de produtos importados de alta intensidade tecnológica e de alta elasticidade-renda culminaria em déficits comerciais crescentes. Segundo o argumento kaldoriano esta situação levaria à restrição externa do balanço de pagamentos e, por conseguinte, a um ciclo vicioso que inviabilizaria o crescimento econômico sustentado. Portanto, é factível afirmar que a economia brasileira está na contramão da lógica estruturalista-kaldoriana.

Diante do exposto, apesar dos esforços do Governo brasileiro em atrair os IDEs com o objetivo de incentivar a absorção, adaptação e difusão da tecnologia importada na estrutura produtiva nacional, não houve transferência de tecnologia e know-how. A falta de articulação, coordenação e a conjuntura econômica interna e externa desfavorável ao lançamento de uma política industrial inviabilizou a obtenção dos resultados pretendidos.

Os bens de capital, assim como os bens mais intensivos em tecnologia, foram majoritariamente importados, e as filiais de empresas transnacionais mantiveram suas atividades de $\mathrm{P} \& \mathrm{D}$ em sua sede, dificultando o processo de transferência de capacidade tecnológica para o Brasil. Sendo assim, os IDEs contribuíram apenas para absorver capacidades produtivas, principalmente via privatização, ocorrendo somente a absorção passiva de tecnologia, o que evidencia a condição 
de atraso científico e tecnológico do País. Há evidências, portanto, de que as políticas brasileiras de promoção à diversificação, ao aumento de competitividade e produtividade da estrutura produtiva nacional foram ineficazes, demostrando que o Brasil possui um SNI com baixo grau de desenvolvimento e papel limitado na indução da atividade econômica.

Como implicação política, o Brasil deveria promover uma política industrial articulada, planejada e consciente de modo a proteger as indústrias nacionais e atrair os IDEs com políticas de incentivo à inovação e estratégias de internalização de P\&D nas empresas brasileiras. Além disso, a busca por parcerias tecnológicas via joint ventures e parcerias público-privadas, por exemplo, deveria ser incentivada. Concomitantemente, o investimento em C\&T e em capital humano deve ser intensificado de modo a desenvolver estratégias de aprendizado ativo com vistas a aproveitar as oportunidades tecnológicas futuras. Em síntese, o Brasil necessitaria adotar políticas com o objetivo de completar o seu SNI de modo a absorver, criar e difundir inovações em sua estrutura produtiva. Assim, a inserção da economia brasileira no comércio internacional de produtos de alta intensidade tecnológica poderá ser concretizada e, logo, o crescimento econômico do país poderá ser sustentado no longo prazo, assim como a China parece ter feito.

\section{REFERÊNCIAS}

Abramovitz, M. (1986). Catching Up, Forging Ahead, and Falling Behind. The Journal of Economic History, 46(2), 385-406.

Albuquerque, E. M., Baessa, A. R., Kirdeikas, J. C. V., Silva, L. A. \& Ruiz, R. M. (2005). Produção científica e tecnológica nas regiões metropolitanas brasileiras. Revista de Economia Contemporânea, 9(3), 615-642.

Araújo, B. C. (2012). Políticas de Apoio à Inovação no Brasil: Uma Análise de sua Evolução Recente. (IPEA Texto para Discussão 1759). Disponível em http:// www.ipea.gov.br/portal/images/stories/PDFs/TDs/td_1759.pdf

Coronel, D. A., Azevedo, A. F. Z., \& Campos, A. C. (2014). Política industrial e desenvolvimento econômico: a reatualização de um debate histórico. Revista de Economia Política, 34(134), 103-119.

Dahlman, C. (2010) Innovation strategies of three of the BRICS: Brazil, India and China-what can we learn from three different approaches. In X. Fu; L. Soete. (Eds.). The Rise of Technological Power in the South. Basingstoke: Palgrave MacMillan.

Delgado, I. G. (2015). Política industrial na China, na Índia e no 
Brasil: Legados, dilemas de coordenação e perspectivas. (IPEA Texto para Discussão $\mathrm{N}^{\circ}$ 2059). Disponível em

http://repositorio.ipea.gov.br/bitstream/11058/3632/1/td_2059_.pdf

Delgado, I. G. et al. Política industrial de países selecionados - Brasil, Rússia, Índia e China BRICs: uma análise ancorada na abordagem das variedades de capitalismo. Brasília: ABDI, (Política Industrial Comparada, volume 10) Disponível em http://www.ufjf.br/seminarios_ppge/files/2014/06/ ABDI-Variedades-de-Capitalismo-e-PI-nna-China-\%C3\%8Dndia-eR\%C3\%BAssia.pdf

Dietzenbacher, E., Van Der linden, J. A., \& STEENGE,

A. E. (1993). The regional extraction method: EC input-output comparisons. Economic Systems Research, 5(2),185-207.

Feijó, C., Oliveira, D. R., \& Lamonica, M. C. (2013). Mudança estrutural nos anos 1990 e 2000: a contribuição das MPME para o crescimento econômico. (BNDES: Programa de Fomento à Pesquisa em Desenvolvimento Econômico; Texto para Discussão). Disponível em https://www.bndes.gov. $\mathrm{br} / \mathrm{wps} / \mathrm{portal} / \mathrm{site} / \mathrm{home} /$ conhecimento/pesquisaedados/estudos/pde/pde/ projetos-selecionados-no-pde-2013

Ferraz, J. C.; Kupfer, D. \& Haguenauer, L. (1995). Made in Brazil: desafios competitivos para a indústria brasileira. Rio de Janeiro: Campus.

Hirschman, A. O. (1958). The strategy of economic development.

New Haven: Yale University Press.

Jayme JR., F. G., \& Resende, M. F. C. (2009). Crescimento econômico e restrição externa: teoria e a experiência brasileira, In R. Michel; L. Carvalho. (Org) Crescimento econômico: setor externo e inflação, Rio de Janeiro: IPEA.

Kaldor, N. (1966). Causes of the Slow Rate of Economic Growth of the United Kingdom. London: Cambridge University Press

Kaldor, N. (1970). The Case for Regional Policies. Scottish

Journal of Political Economy, 17(3), 337-348.

Kaldor, N, \& Mirrlees, J. A. (1962). A New Model of Economic Growth. Review of Economic Studies, 29(3), 174-192.

Kupfer, D. (1998). Trajetórias de Reestruturação da Indústria

Brasileira após a abertura e Estabilização. 185f. (Tese de Doutorado em Economia). Instituto de Economia, Universidade Federal do Rio de Janeiro, Rio de Janeiro. Kupfer, D. (2005). Tecnologia e emprego são realmente antagônicos? In J. Sicsú; L. F. Paula; R. Michel (Orgs.). Novo-Desenvolvimentismo: um projeto nacional de crescimento com equidade social. Barueri: Manole.

Lall, S. (1992). Technological capabilities and industrialization.

World Development, 20(2), 165-186. 
. (2000). The technological structure and performance of developing country manufactured exports, 1985-98. Oxford Development Studies, 28(3), 337-69.

Lamonica, M. T., \& Feijó, C. (2011). Crescimento e industrialização no Brasil: uma interpretação à luz das propostas de Kaldor. Revista de Economia Política, 31(1), 118-138.

Leontief, W. (1941). The Structure of American Economy, 1919-1929. Cambridge: Harvard University Press, MA. Masiero, G., \& Coelho, D.B. (2014). A política industrial chinesa como determinante de sua estratégia going global. Revista de Economia Política, 34(1), 139-157.

Mccombie, J. L., \& Roberts, M. (2002). The role of the balance of payments in economic growth, In M. Setterfield. (Ed.). The Economics of Demand-led Growth: Challenging the Supply-side Vision of the Long Run. Cheltenham: Edward Elgar Publishing.

Mccombie, J. S. L., \& Thirlwall A. P. (1994). Economic growth and the balance of payments constraint. New York: St. Martin's Press.

Miller, R. E., \& Blair, P. D. (2009). Input-output analysis: foundations and extensions. (2th ed). New York: Cambridge University Press.

Nassif, A. L. (2000). A articulação das Políticas Industrial e

Comercial nas Economias em Desenvolvimento contemporâneas: Uma Discussão analítica. Revista de Economia Política, 20(2), 3-22.

Nonnenberg, M. B. (2010). China: estabilidade e crescimento econômico. Revista de Economia Política, 30(2), 201-218.

Organisation For Economic Co-operation And

Development - OECD (2006). Input-Output Database, edition 2006. Disponível em http://www.oecd.org/industry/ind/input-outputtableslatesteditionacces stodata.htm

Oliveira, D. R. (2011). O processo de mudança estrutural no pós-1990: uma análise da heterogeneidade produtiva na perspectiva kaldoriana. 156f. (Tese de Doutorado em Economia). Universidade Federal Fluminense, Niterói.

Palermo, P. U., Porsse, A. A., \& Peixoto, F. C. (2010).

Relações setoriais e interdependência regional da economia gaúcha: análise com um modelo inter-regional de insumo-produto. Ensaios FEE. 31(1), 113-148.

Pasinetti, L. L. (1983). Nicholas Kaldor: a few personal notes.

Journal of Post Keynesian Economics, 5(3), 331-340.

Patel, P., \& Pavitt, K. (1994). National Innovation Systems: why they are important, and how they might be measured and compared. Economics of innovation and New Technology. 3(1), 77-95.

Prebisch, R. (1950). The Economic Development of Latin America and its 
Principal Problems. Lake Sucess, New York: CEPAL. Disponivel em https://repositorio.cepal.org/bitstream/handle/11362/29973/002_ en.pdf? sequence $=1 \&$ isAllowed $=\mathrm{y}$

Rasmussen, P. (1956). Studies in intersectorial relations. Amsterdam, North Holland: Einar Harcks Forlag

Resende, M. F. C., \& Torres, D. R. (2008). National Innovation

System, Trade Elasticities and Economic Growth. In Anais do XXXVI Encontro Nacional de Economia (ANPEC), Salvador.

Rodrigues, R. L., Parré, J. L., Moretto, A.C., \& Alves,

A. F. (2007). Transformações na estrutura produtiva da economia paranaense nos anos 80 e 90. Revista de Economia Aplicada, 11(1), 73-93.

Silva, J. H. F. (2017). Alterações na estrutura produtiva no Brasil e na China: um estudo comparativo das políticas industriais recentes. 2017. (Tese de Doutorado em Ciência Política) - Universidade Federal de Pernambuco, Recife.

Singer, H. (1950). The Distribution of Gains Between Investing and Borrowing Countries. American Economic Review, 40(2), 473-485

Suzigan, W., \& Furtado, J. Política industrial e desenvolvimento. Revista de Economia Política, 26(2), 163-185.

Thirlwall, A. P. (1979). The balance of payments constraint as an explanation of international growth rates differences. Banca Nazionale del Lavoro Quarterly Review, 32(128), 45-53

. (1997). Reflections on the concept of balance-of-

payments-constrained growth. Journal of Post Keynesian Economics, 19(3), 377-385. . (2001). The relation between the warranted growth rate,

the natural growth rate and the balance of payments equilibrium growth rates. Journal of Post Keynesian Economics, 24(1), 81-88.

Thirlwall, A. P., \& Hussain, M. N. (1982). The balance of payments constraint, capital flows and growth rate differences between developing countries. Oxford Economic Papers, 34(3), 498-510.

Vieira, W. C. (1996). Uma análise dos efeitos econômicos de estratégias de promoção de exportações. Análise Econômica. 14(25/26), 52-62.

Vieira, F. L., \& Veríssimo, M. P. (2009). Crescimento econômico em economias emergentes selecionadas: Brasil, Rússia, Índia, China (BRIC) e África do Sul. Economia e Sociedade, 18(3), 513-546.

Viotti, E. B. (2002). National learning systems: a new approach on technological change in late industrializing economies and evidences from the cases of Brazil and South Korea, Technological Forecasting and Social Change, 69(7),653-680. 
World Bank (2018). World Development Indicators Database.

Foreign direct investment, net inflows (\% of GDP), 1995-2005.

World Bank. Disponível en https://data.worldbank.org/indicator/BX.KLT.DINV. WD.GD.ZS

WTO - World Trade Organization. International trade statistics

2006. Disponível em http://www.wto.org/english/res_e/statis_e/statis_e.htm

Yamano, N., \& Ahmad, N. (2006). The OECD Input-Output

Database: 2006 Edition. (OECD Science, Technology and Industry Working Papers 2006/8), Paris: OECD Publishing. DOI: https://doi. org/10.1787/308077407044

(C) 2019 por los autores; licencia otorgada a la Revista Estudios Económicos. Este artículo es de acceso abierto y distribuido bajo los términos y condiciones de una licencia Atribución-No Comercial 3.0 Unported (CC BY-NC 3.0) de Creative Commons. Para ver una copia de esta licencia, visite http://creativecommons.org/ licenses/by-nc/3.0/ 
